\title{
M-Learning and Student Engagement in English Language Teaching: The Case of First-YearUndergraduate Students at Ecole Normal Superieur,Algeria
}

\author{
Imane Tiahi \\ The University of Northampton
}

\begin{abstract}
:
The aim of the current paper is to explore the attitudes of teachers, students, and institutional leaders toward m-learning and student engagement within Algerian context. Researches explain such practices bear traditional approach and overlooks modern teaching methods such as mlearning. That is why the research output of exploring student engagement in respect of mlearning was obtained from the following aims (1) To evaluate the current practice of English language teaching within Algerian higher education institutions, (2) To explore how social constructivism theory and m-learning help student engagement in the classroom and (3) To explore the feasibility and acceptability of m-learning amongst institutional leaders. The methodology underpins a case study and action research. For the case study, the researcher engaged with seven teachers, four institutional leaders, and 30 students. For the action research, the researcher applied an intervention course to investigate the possibility and implications for future implementation of m-learning in higher education institutions. The results were deployed using thematic analysis. The research outcome showed that the disengagement of students in English language learning has many aspects. As seen from the interviews from the teachers, the researcher found that they do not have enough resources except for using ppt for some teacher. According to them, the teaching method they are using is mostly based on Grammar Translation Method. Teachers informed that students are disengaged because they have psychological barriers. In classroom setting, the students are conscious about social approval from the peer, and thus if they are to face negative reinforcement which would damage their image, it is seen as a preventive mechanism to be scared of making mistakes. This was also very reflective in this finding. A lot of other arguments can be given for this claim; however, in Algerian setting, it is usual practice where teachers do not provide positive reinforcement which is open up students for possible learning. Thus, in order to overcome the psychological barriers, proper measures can be taken. Unlike institutional leaders, it was evident that teachers and students provided positive feedback for using m-learning. It is not only motivating but also engaging in learning processes. Apps such as Kahoot, Padlet and Slido were well received and thus can be taken further to examine its higher impact in Algerian context. Thus, in the future, it will be important to implement m-learning effectively in higher education to transform the current traditional practices into modern, innovative and active learning. Persuasion for this change for institutional leaders may be challenging; however, its long-term benefits can be reflective from the current research paper.
\end{abstract}

Keywords: Algerian context, m-learning, social constructivism, student engagement 